\title{
Study on Attenuation Properties of Surface Wave of AE Simulation Source Based on OPCM Sensor Element
}

\author{
Ziping Wang $\mathbb{D}^{1}{ }^{1}$ Xian Xue, ${ }^{1}$ Xingjia Li $\mathbb{D}^{1},{ }^{1}$ Zhengxuan Jiang, ${ }^{1}$ and Karthik Reddy ${ }^{2}$ \\ ${ }^{1}$ Faculty of Civil Engineering and Mechanics, Jiangsu University and National Center for International Research on Structural Health \\ Management of Critical Components, Zhenjiang 212013, China \\ ${ }^{2}$ Department of Mechanical \& Aerospace Engineering, North Carolina State University, Raleigh, NC 27606, USA
}

Correspondence should be addressed to Ziping Wang; wzpxx2004@126.com

Received 7 December 2017; Revised 13 February 2018; Accepted 28 February 2018; Published 12 April 2018

Academic Editor: Aniello Falco

Copyright (c) 2018 Ziping Wang et al. This is an open access article distributed under the Creative Commons Attribution License, which permits unrestricted use, distribution, and reproduction in any medium, provided the original work is properly cited.

It is of great significance to grasp the ultrasonic attenuation characteristics of materials for the nondestructive testing of materials. The dynamic properties of a piezoelectric composite material (OPCM) with self-developed transverse anisotropy have been analyzed using the experiment in this work. The OPCM sensor is attached to the surface of the iron plate and concrete structures to sense the surface waves generated by acoustic emission (AE). The experiment results show that OPCM sensor elements have unique advantages compared to piezoelectric ceramic materials (PZT). Further, by comparing the signals of isotropic and anisotropic materials, the attenuation characteristics of surface waves propagating in different materials are studied, and a new method for measuring the attenuation coefficient of surface waves is demonstrated.

\section{Introduction}

Surface waves have been widely used for damage detection in many engineering structures [1-3]. The sensors, which receive the surface waves, play an important role in damage detection. In 1885, Lord Rayleigh discovered surface acoustic waves in semi-infinite isotropic solid bodies and has since been used for signal processing techniques [4], including filtering [5], delay [6], pulse compression [7], correlation, and convolution [8]. It has been used in such fields as radar, aerospace, communications, and damage detection $[9,10]$. Moreover, with the development of SAW technology, various kinds of new low-loss sensors such as Rayleigh-type SAW, shear-type SAW, and BG wave were developed. The generation and emergence of various sensor simulation theories are the conditions for the development and application of new fields of SAW sensors with excellent performance [11]. It is due to the essential characteristic of SAW that sound waves propagate along the substrate surface, making SAW sensitive to physical, chemical, or other mechanical perturbations of its surface, thereby making it possible to produce a wide variety of highly sensitive sensors [12]. The basic principle is that when the physical or chemical parameters act on the surface of a SAW transducer is changed, the disturbance of SAW propagation will cause the variation of velocity and amplitude. The corresponding damage detection signals will be recorded by SAW sensors.

In addition to good flexibility, high strength, large ultimate strain, light weight, and other advantages provided by piezoelectric materials, OPCM sensor elements have a flat cross-anisotropic characteristic that can distinguish the planar structure of various components of a stress wave [13-15]. In this study, the feasibility of frequency chosen by $\mathrm{AE}$ broken pencil signals was verified by testing natural frequency ranges of SAW sensors. The attenuation characteristics of surface wave generated by AE simulation source in iron and concrete plate is tested by broken lead experiments. When the sample thickness is more than 2 to 3 wavelengths, the stress waves excited on the surface of the sample are mainly Rayleigh waves, which propagate longer distances. This is because the spread of the wave attenuation is much smaller than the longitudinal and transverse 




FIgURE 1: 1-1 OPCM sensing element structure.

TABle 1: Piezoelectric ceramics' physics and electricity performance.

\begin{tabular}{|c|c|c|c|c|c|c|c|c|c|c|c|c|c|}
\hline \multirow{2}{*}{$\begin{array}{l}\text { Density } \\
10^{3} \mathrm{~kg} / \mathrm{m}^{3}\end{array}$} & \multirow{2}{*}{$\begin{array}{c}\text { Curie } \\
\text { temperature: }{ }^{\circ} \mathrm{C}\end{array}$} & \multicolumn{3}{|c|}{$\begin{array}{c}\text { Compliance constant } \\
10^{-12} \mathrm{~m}^{2} / \mathrm{N}\end{array}$} & \multirow{2}{*}{$\begin{array}{c}\text { Poisson's } \\
\text { ratio } \\
\mu\end{array}$} & \multicolumn{2}{|c|}{$\begin{array}{l}\text { Dielectric } \\
\text { constant }\end{array}$} & \multicolumn{3}{|c|}{$\begin{array}{c}\text { Piezoelectric } \\
\text { constant } 10^{-12} \mathrm{C} / \mathrm{N}\end{array}$} & \multicolumn{3}{|c|}{$\begin{array}{c}\text { Coupling } \\
\text { coefficient: } \%\end{array}$} \\
\hline & & $S_{11}^{\mathrm{E}}$ & $S_{33}{ }^{\mathrm{E}}$ & $S_{55}^{\mathrm{E}}$ & & $\varepsilon_{33}{ }^{\sigma}$ & $\varepsilon_{11}^{\sigma}$ & $d_{31}$ & $d_{33}$ & $d_{15}$ & $k_{31}$ & $k_{33}$ & $k_{15}$ \\
\hline 7.45 & 260 & 15 & 9 & 22 & 0.32 & 2100 & 2400 & 245 & 530 & 816 & 36 & 70 & 68 \\
\hline
\end{tabular}

waves. Therefore, Rayleigh waves generated by the broken lead can be used to assess the performance of the sensor element and to analyze the attenuation characteristics effectively.

\section{Dynamic Performance Analysis of 1-1 OPCM Sensor Element}

The first step to construct OPCM elements is to design the piezoelectric phase of the element. Additionally, the volume ratio of the piezoelectric in the composite should be taken into account, including the effects of the elastic constants of the polymer material to impact the OPCM elements' mechanical and electric characteristics. Taking the above factors into account, the OPCM sensor element was developed [16, 17], as shown in Figure 1. The length of the OPCM sensor element $l$ is $13.8 \mathrm{~mm}$, its width $b$ is $4 \mathrm{~mm}$, and is thickness $h$ is $0.7 \mathrm{~mm}$. The electrode interval $a$ is $1 \mathrm{~mm}$, and the electrode width $d$ is $0.1 \mathrm{~mm}$. The piezoelectric phases of the OPCM sensor are cut from the same monolithic and already polarized P-51 piezoelectric ceramic plate to ensure that the piezoelectric material properties are consistent. Table 1 shows the material properties of P-51 PZT. The substrate material of DAD-40 is conductive epoxy adhesive. The shear strength at normal temperature is $14.7 \mathrm{MPa}$, and the volume resistivity is less than $1.0 \times 10^{-3} \Omega \mathrm{cm}$. The interdigitated electrodes were shown in Figure 1, and two sides of the electrode can generate opposite electric polarity. The manufacturing process of two electrodes with opposite polarities was provided. It can form a good insulation tape to prevent electrical leakage. The resistance of the insulated region, between the two electrodes, is measured, and it is found to be more than $200 \mathrm{M} \Omega$.

In order to obtain the frequency response of OPCM sensor element and set the range of frequency, the oscilloscope was used to record the waveform from two different directions in the experiment. When the excitation frequency was changed point by point, the corresponding variation voltage was recorded by the oscilloscope, and then the resonant frequency of two component voltages from directions $x$ and $y$ with OPCM sensor element can be gotten. When the test frequency changes from $20 \mathrm{kHz}$ to $400 \mathrm{kHz}$, the OPCM sensing element receives the amplitude and encrypts the measuring point when the amplitude suddenly increases. The frequency is the resonant response frequency of the sensing element in this direction. Figure 2 shows the amplitude-frequency characteristic curve obtained from the frequency and voltage testing experiment.

The resonance frequency of the OPCM sensor in direction 3 is $173 \mathrm{kHz}$. The maximum amplitude at the resonant frequency is $41 \mathrm{mV}$, while the 1-direction amplitude is low, which shows the orthotropic performance.

\section{Attenuation Characteristic Experiment}

3.1. Specimen Preparation. The iron plate used in the experiment is of size $1000 \mathrm{~mm} \times 1000 \mathrm{~mm} \times 20 \mathrm{~mm}$ with density of $7.8 \times 10^{3} \mathrm{~kg} / \mathrm{m}^{3}$, whereas the size of the standard curing concrete specimen is $700 \mathrm{~mm} \times 700 \mathrm{~mm} \times 200 \mathrm{~mm}$, and the density is $2452 \mathrm{~kg} / \mathrm{m}^{3}$. The concrete specimen is prepared with the mass mixing proportion (cement:gravel:sand: 


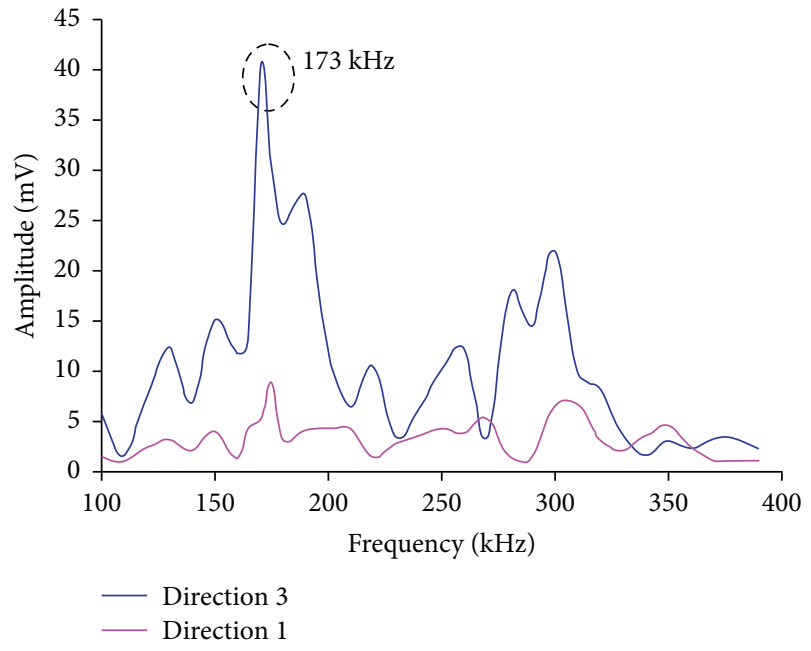

FIGURE 2: Amplitude-frequency curve.

water) of $1: 2.86: 1.25: 0.49$, and the maximum size of gravel is $16 \mathrm{~mm}$, and the water-cement ratio is 0.49 .

The OPCM elements should be polished first before pasting it to the surfaces of the iron plate and concrete specimen with $\mathrm{AB}$ glue. The interval from the border is $200 \mathrm{~mm}$. The $\mathrm{HB}$ pencil with a diameter of $0.5 \mathrm{~mm}$ and length of $2.5 \mathrm{~mm}$ is used in the broken lead experiments. The signal from the pencil broken at $30^{\circ}$ at each measuring point simulates the AE signal in the structures.

3.2. Experiment Equipment and Experiment Content. Figure 3 shows the experimental setup used for this work. The dashed lines indicate the test lines of the polarization direction of sensing elements of the OPCM sensor. The interval of the pencile-broken points is $10 \mathrm{~mm}$. The first OPCM sensor is used to test the directional performance of polarization and wave attenuation characteristic. By using a second OPCM sensor, the surface wave velocities of two materials can be calculated from the measured time difference. In this experiment, the velocity error depends on the sampling length. The Agilent54820A waveform generator, whose sampling length is set as 32768 pts and sampling frequency is set to $2.5 \mathrm{MHz}$, is used to break the pencil with band frequency from $50 \mathrm{kHz}$ to $400 \mathrm{kHz}$ [18] at given points along the direction of the OPCM sensor. The experimental testing setups of two kinds of plate are as shown in Figure 4.

In the test, the signals are collected from the iron plate and concrete along the direction of polarization of the OPCM sensing element and at every $15^{\circ}$ along the direction from $0^{\circ}$ to $90^{\circ}$ for different lead lengths. The velocity of the surface wave was tested in the iron plate and concrete, separately.

\section{Experimental Results and Discussion}

4.1. Surface Wave Propagation Characteristics in Different Materials. Figure 5 shows the waveform generated from the surface of the iron and concrete specimens with SAW sensors, respectively. Three typical waveforms tested by OPCM SAW sensors were selected to analyze. The results

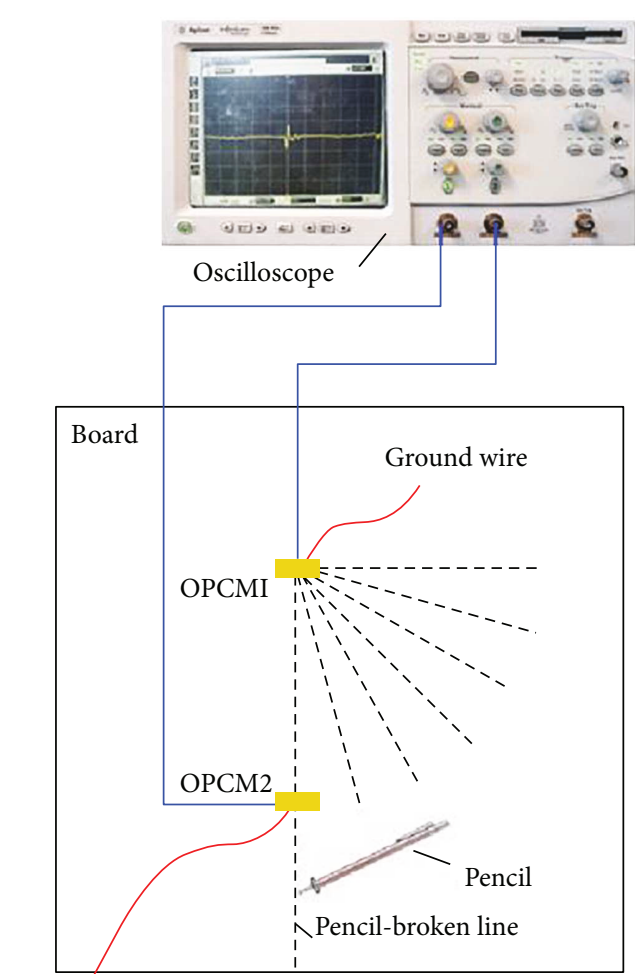

Ground wire

FIgURE 3: Experimental setup.

show that the wave amplitudes were attenuated on the iron plate more regularly than that on the concrete. This is because the concrete is an anisotropic material, and particles of different sizes cause reflection and scattering. Next, the amplitudes of the concrete are smaller than those of the iron plate, and this indicates that the attenuation of the wave in concrete is faster. Figure 6 shows the spectrums of the typical waves in concrete plate that were analyzed, and it is analogous in the iron plate. The resonance frequency testing results indicates that the SAW sensor can receive pencil-broken signals with it's special frequency. The velocity of SAW can be calculated from the signal travel time difference. It is found that the surface velocity is $2958 \mathrm{~m} / \mathrm{s}$ in the iron plate and $2103 \mathrm{~m} / \mathrm{s}$ in the concrete material. The surface velocity values validate the correctness and feasibility to test the Rayleigh wave velocity. Before recording the signals, the pencil core must be broken at least three times to get the stable signals. The experiments are repeated for a number of times, and the surface velocity values obtained from each run are consistent with the nondispersion characteristics of Rayleigh wave, and the recorded signals are considered mainly to be Rayleigh waves.

The OPCM sensor was stuck on the surface of iron plate and concrete specimen. The signals from different angle points can be collected $200 \mathrm{~mm}$ away from the center of the senor. Only $20 \mathrm{mV}$ amplitude peak can be received in the polarization direction $\left(90^{\circ}\right)$, and no signals are received in other directions. This phenomenon further verifies the good cross-anisotropy of the developed OPCM sensor elements. 


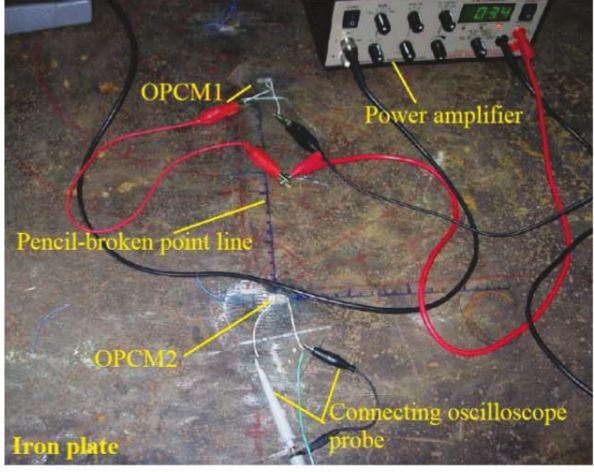

(a) Attenuation characteristic testing experimental setup of the metal plate

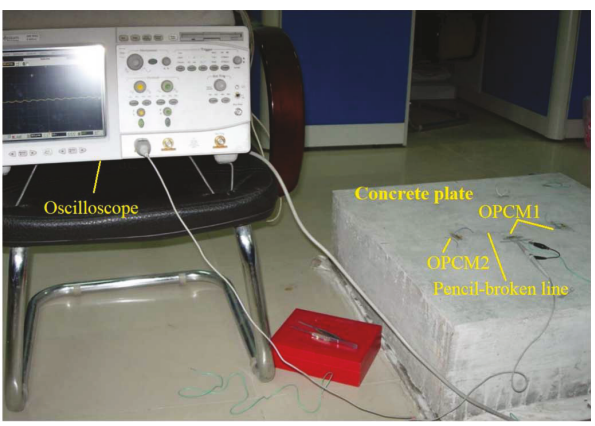

(b) Attenuation characteristic testing experimental setup of the concrete plate

Figure 4: Two kinds of plate testing sample.

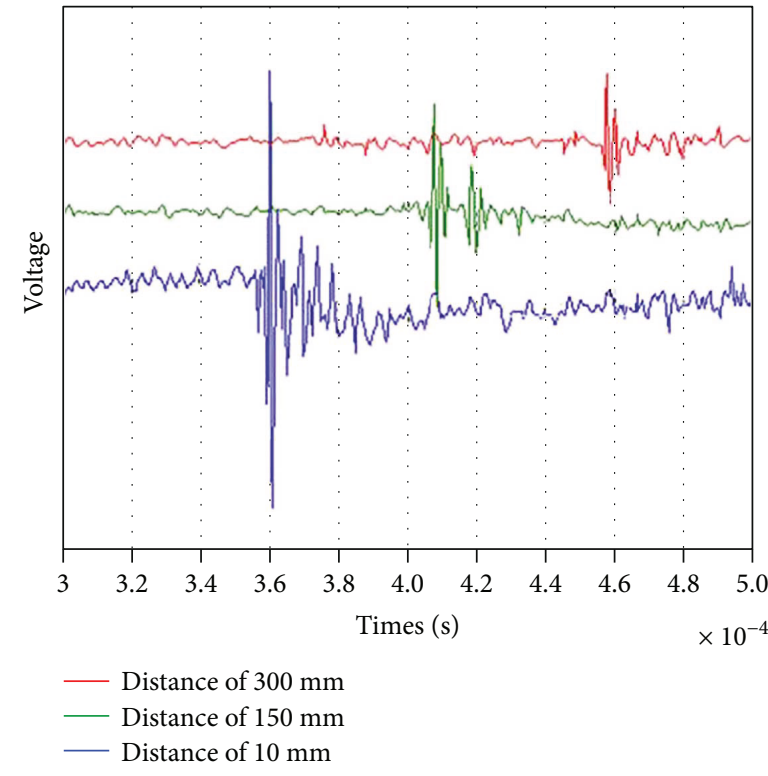

(a) Different distance waveforms in metal plate

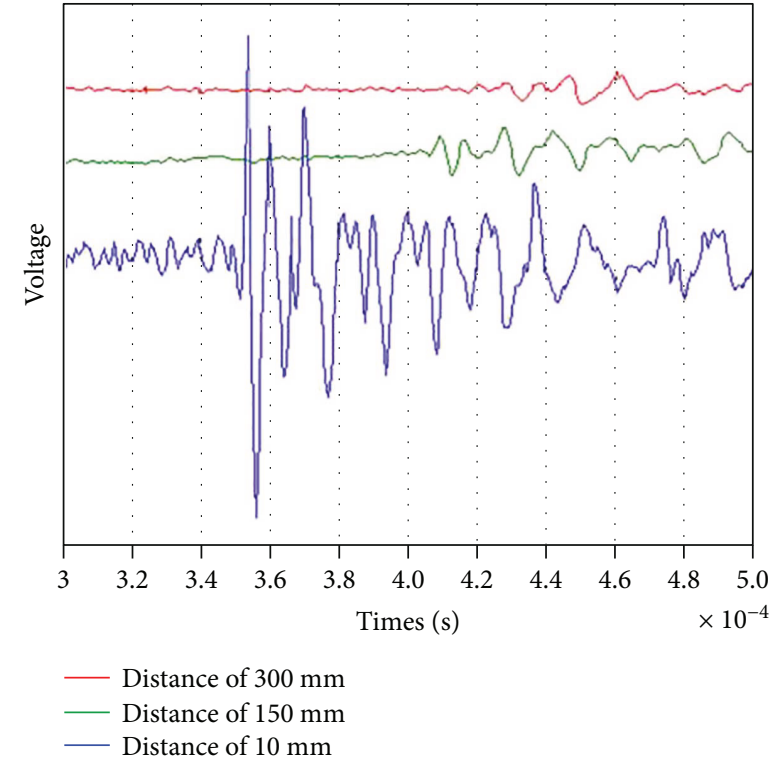

(b) Different distance waveforms in concrete plate

Figure 5: Typical waveform record in metal and concrete plates.

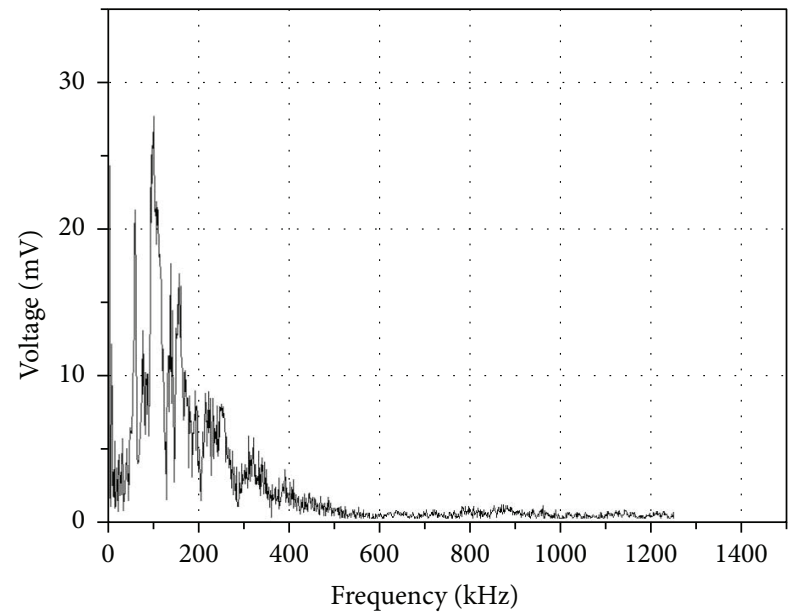

FIgURE 6: Spectrum analysis diagram of typical signals.
4.2. Wave Attenuation Characteristics of Different Materials. In the experiment, the signal generated by the by broken pencil is very weak. A lead signal was measured every $10 \mathrm{~mm}$ away from the center of the sensing element in the polarization direction of the sensing element, and the corresponding surface wave amplitude is calculated. Figure 7 shows the distance-amplitude curve. The results show that the maximum propagation distance measured in the iron plate is $460 \mathrm{~mm}$, and the attenuation is observed up to a distance pf $260 \mathrm{~mm}$. In case of the concrete specimen, the maximum distance measured is $300 \mathrm{~mm}$, and the attenuation is observed up to a maximum distance of $150 \mathrm{~mm}$. The results show that the amplitude of the wave decreases with propagation distance for both concrete and iron plates. However, the wave attenuates quickly, with propagation distance, in concrete compared to iron. In order to study the attenuation performance of surface wave, a mathematical 


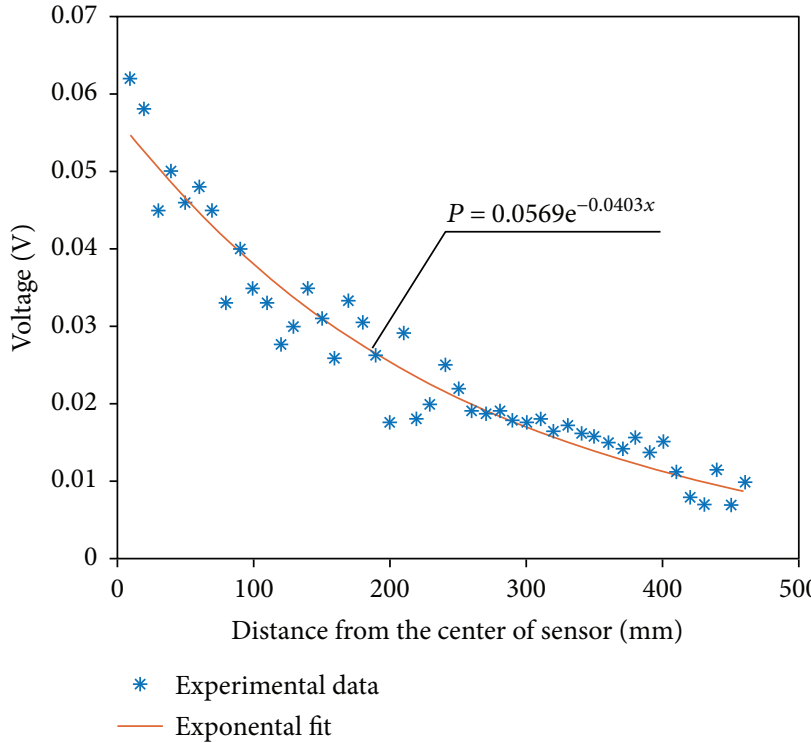

(a) The attenuation curve of the iron plate

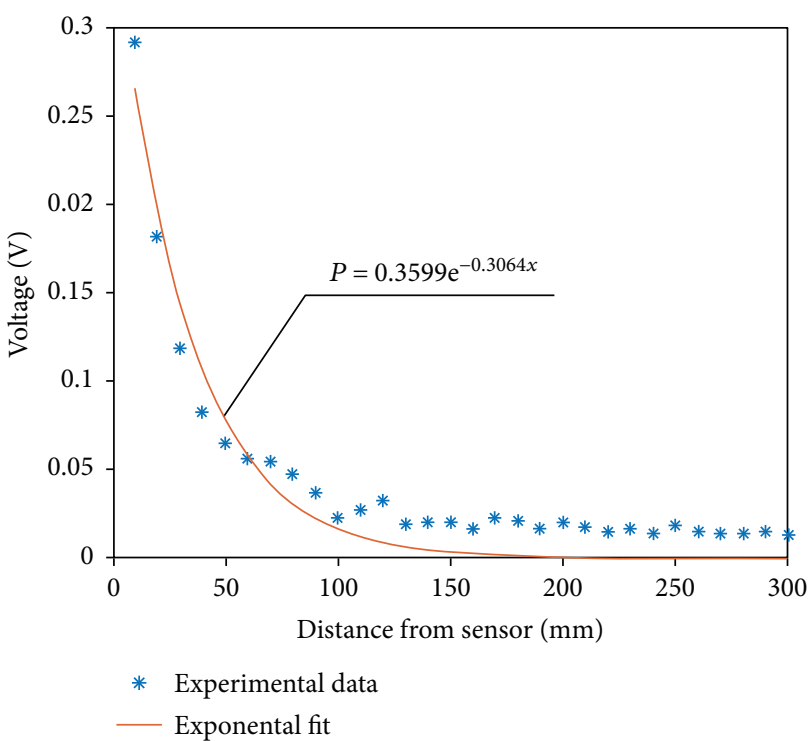

(b) The attenuation curve of the concrete specimen

FIGURE 7: Relation between peak value and propagation distance.

fit is obtained from the amplitude data of Figure 7 and the propagation distance. The results show that the amplitude peak shows an exponential decline with the propagation distance $x$ as shown in Figure 7. The attenuation law of the surface wave is an exponential decay, which can be expressed as $P=A e^{-n x}$, where $A$ is the constant related to the material, and $n$ is the attenuation coefficient that controls the surface waves decay rate. Figure 7 shows that the attenuation coefficients of SAW are 0.0403 and 0.3064 in iron and concrete specimen, respectively. It has provided a method to test the attenuation coefficients.

\section{Conclusions}

The developed AE tests are successfully conducted to study the wave propagation phenomena in the iron plate and concrete specimens using the 1-1 OPCM sensor. The single-point frequency-amplitude test results in its resonant frequency, which proves the feasibility of the AE broken pencil signal test and can be used in subsequent experiments to provide excitation frequency selection. The experiment is conducted multiple times on the same material using different OPCM sheets. The attenuation characteristics of the surface wave and wave speeds are obtained from the experiments. The attenuation characteristics of surface wave generated by the $\mathrm{AE}$ simulation source in iron and concrete materials are studied. The characteristics of the surface wave and its propagation velocity in different materials are analyzed. The waveforms recorded at different positions on iron and concrete plates show that the increasing peak values of the surface wave deviated from the sensing element are decreased rapidly exponentially and decayed rapidly in concrete. According to the material attenuation coefficient obtained experimentally, it can provide guidance for the study of amplitude compensation and impedance matching in multielement transducers.

\section{Conflicts of Interest}

The authors declare that there is no conflict of interests regarding the publication of this paper.

\section{Acknowledgments}

This work was financially supported by the National Natural Science Foundation of China (Grant nos. 11402101 and 11520101001) and Jiangsu University Foundation (14JDG022).

\section{References}

[1] J. Y. Kim and S. I. Rokhlin, "Surface acoustic wave measurements of small fatigue cracks initiated from a surface cavity," International Journal of Solids and Structures, vol. 39, no. 6, pp. 1487-1504, 2002.

[2] C. Y. Cheng, S. S. Huang, C. M. Yang, K. T. Tang, and D. J. Yao, "Detection of third-hand smoke on clothing fibers with a surface acoustic wave gas sensor," Biomicrofluidics, vol. 10, no. 1, article 011907, 2016.

[3] R. Yasukuni, R. Fukushima, T. Iino, and Y. Hosokawa, "Pulsed-laser-activated impulse response encoder: sensitive detection of surface elastic waves on biomimetic microsized gel spheres," Applied Physics Express, vol. 10, no. 11, article 117001, 2017.

[4] M. F. Lewis, "Rayleigh waves-a progress report," European Journal of Physics, vol. 16, no. 1, pp. 1-7, 1995.

[5] J. Ivanov, C. B. Park, R. D. Miller, and J. Xia, "Analyzing and filtering surface-wave energy by muting shot gathers," Journal of Environmental and Engineering Geophysics, vol. 10, no. 3, pp. 307-322, 2005.

[6] B. D. Zaitsev, I. E. Kuznetsova, N. E. Zemnyukov, V. I. Proidakov, and A. A. Teplykh, "Plate acoustic waves for low frequency delay line delaying signals up to $0.5 \mathrm{~ms}$," Physics Procedia, vol. 3, no. 1, pp. 533-539, 2010. 
[7] F. G. Herring, P. M. Krencik, and C. F. Vasile, "High performance surface-wave pulse compression," in 1973 Ultrasonics Symposium, pp. 472-477, Monterey, CA, USA, November 1973.

[8] E. A. Ash and E. G. S. Paige, Rayleigh-Wave Theory and Application, Springer, Berlin Heidelberg, 1985.

[9] V. Giurgiutiu and J. Bao, "Embedded ultrasonic structural radar with piezoelectric wafer active sensors for the NDE of thin-wall structures," in ASME 2002 International Mechanical Engineering Congress and Exposition, pp. 31-38, New Orleans, LA, USA, November 2002.

[10] X. Yan, W. Huang, S. R. Kwon, S. Yang, X. Jiang, and F. G. Yuan, "A sensor for the direct measurement of curvature based on flexoelectricity," Smart Materials and Structures, vol. 22, no. 8, article 085016, 2013.

[11] T. Wang, R. Green, R. Nair et al., "Surface acoustic waves (SAW)-based biosensing for quantification of cell growth in $2 \mathrm{D}$ and 3D cultures," Sensors, vol. 15, no. 12, pp. 3204532055, 2015.

[12] V. Lonescu, "Design and analysis of a Rayleigh saw resonator for gas detecting applications," Romanian Journal of Physics, vol. 60, pp. 502-511, 2015.

[13] Y. Luo and B. Q. Tao, "The OPCM strain gauges for strain and stress measurement of orthotropic material structures," Acta Mechanica Solida Sinica, vol. 13, no. 4, pp. 337-345, 2000.

[14] Z. P. Wang, Y. Luo, G. P. Zhao et al., "Design and optimization of an OPFC ultrasonic linear phased array transducer," International Journal of Mechanics and Materials in Design, vol. 13, pp. 1-13, 2015.

[15] J. S. Popovics, W. Song, J. D. Achenbach et al., "One-sided stress wave velocity measurement in concrete," Journal of Engineering Mechanics, vol. 124, pp. 1345-1353, 2016.

[16] Z. Wang, Y. Luo, and T. Sun, "Design and validation of an orthotropic piezoelectric composite material phased array sensor used to nondestructive detection," Sensor Letters, vol. 13, no. 10, pp. 852-856, 2015.

[17] Z. Wang, Y. Luo, G. Zhao, B. Q. Xu, and F. G. Yuan, "Design of an OPCM phased array transducer for damage detection in a concrete structure," Research in Nondestructive Evaluation, vol. 27, no. 4, pp. 204-215, 2016.

[18] A. Gu, Y. Luo, and B. Xu, "Continuous condition monitoring of reinforced concrete using an active diagnosis method," Structural Health Monitoring, vol. 15, no. 1, pp. 104-112, 2016. 


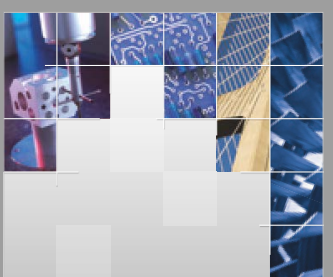

\section{Enfincering}
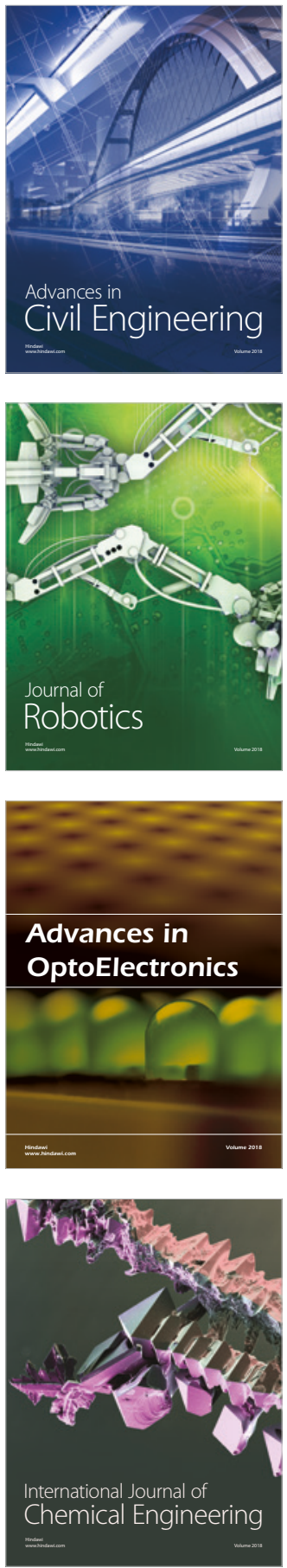



\section{Rotating \\ Machinery}

The Scientific World Journal

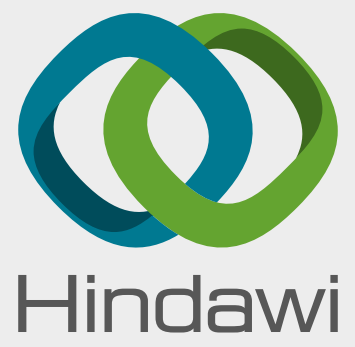

Submit your manuscripts at

www.hindawi.com
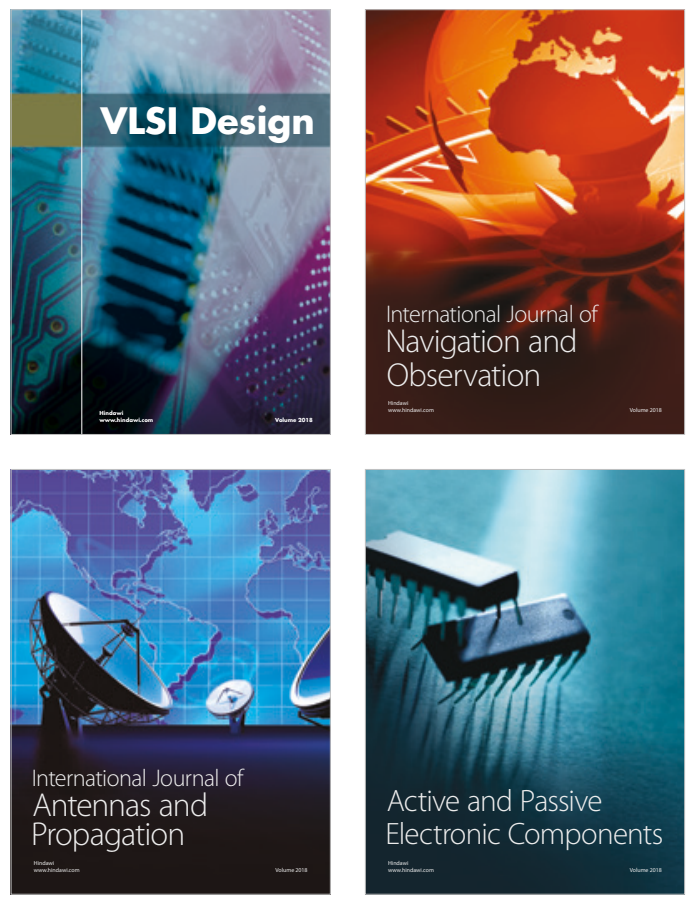
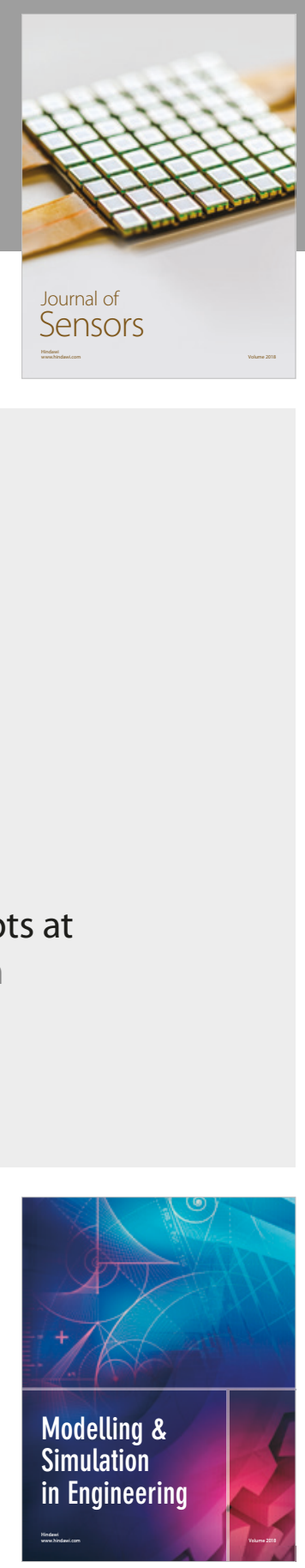

\section{Advances \\ Multimedia}
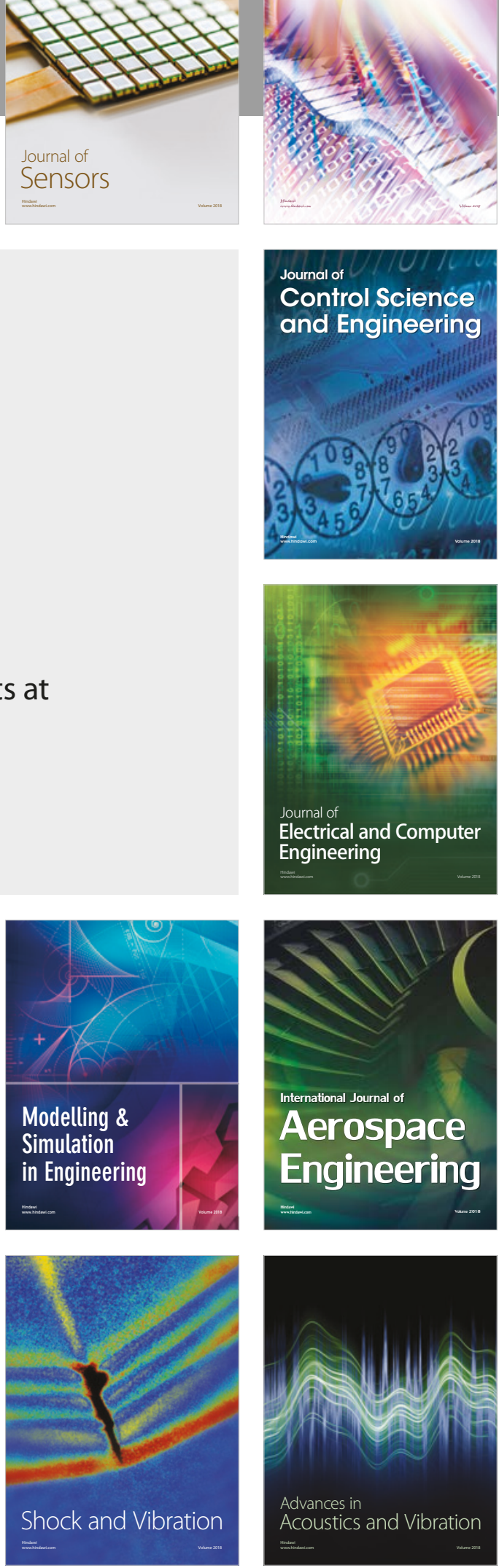